Minorization and the process of (de)minoritization: the case of Kali'na in French

\title{
Guiana
}

Isabelle Léglise and Sophie Alby

2006, International Journal of the Sociology of Language $\mathrm{n}^{\circ} 182,67-86$.

\author{
Isabelle Léglise \\ CNRS UMR CELIA, \\ BP 8 \\ 94801 Villejuif, France \\ Tel.:+33 603862455 , Fax: +33149583827 \\ Email: leglise@univ-tours.fr
}

\begin{abstract}
(176 words)
This article examines the case of Kali'na, a minority Indigenous language of French Guiana, from the point of view of descriptive categories available in the literature (namely dominated language, minoritized language, endangered language). These terms are discussed, favouring more dynamic categories which focus on processes (minoritization/deminoritization). The article uses both micro- and macrosociolinguistic levels of analysis. At the macro level, indicators are proposed to gauge the minorization of Kali'na as it occurs on the scale of Guiana as a whole, by observing attitudes towards Kali' na language and culture, particularly as expressed in the media and in epilinguistic comments made by speakers. At the local level, we explore the effects of the recognition by the State of a Kali'na township and their influence on language minoritization in the village and more generally at the level of the linguistic community. We also attempt to determine to what extent, as far as interactions are concerned, alternations and code switching between Kali'na and French might constitute indicators of the process of minoritization or deminoritization or of language death currently underway.
\end{abstract}




\section{Minorization and the process of (de)minoritization: the case of Kali'na in French Guiana}

\section{Introduction}

The concept of diglossia, according to the broad definitions of Fishman (1971) and Ferguson $(1991)^{\mathrm{i}}$, has had a significant impact on the field of language contact studies, to the point that the "high variety/low variety" model often influences the scientific perception of any situation in which one or more contact or official languages are in contact with languages spoken by smaller groups, also known as minority languages (Haugen 1989). Macrolinguistic descriptions of multilingual situations seldom escape this influence, even when they are located - as it is the case here - outside models of linguistic conflict such as Aracil (1965) or Lafont (1997) whereby linguistic cohabitation is seen as a pairing of dominant language(s) versus dominated. Furthermore, the epilinguistic comments of speakers who belong to a linguistic minority often refer to hierarchies or conflicts between languages, to the point that the researcher is faced with emic categories which mirror the high/low and dominant/dominated models.

As such, in looking at the macrolinguistic situation of the French Overseas Department of Guiana, one tends to see uneven relationships between languages: an official language (French), contact languages (essentially Guyanese Creole and French) and vernacular languages, some of which are regional (Amerindian languages such as Kali'na and Wayana, 
English-based creoles like Ndyuka and Aluku, etc) while others are a product of immigration (and are vernacular in Guiana, such as Haitian Creole, Brazilian Portuguese, Spanish, etc).

A global approach to the languages of French Guiana, like the one presented above, gives us a rapid overview of the linguistic situation of the department. It is, however, imperfect on several levels: in terms of geography, in terms of the hierarchy between local and global levels, and in terms of the dynamics involved. For one thing, the approach needs to be qualified as far as Guyanese regional particularities are concerned, as seen in the appended map of regional languages: the vernacular languages are positioned in different ways across the territory, making it difficult to make any generalizations. Another point is that the language dynamics of each region are not necessarily the same and potentially contradict the global conclusions. For example, in Western Guiana, and particularly in Saint-Laurent of Maroni, Guyanese Creole is in strong competition with English-based creoles, namely Nenge variants (mostly Ndyuka) ${ }^{\mathrm{ii}}$ and Sranan Tongo (a contact creole from Surinam), allowing us to see the emergence of new contact languages. At the local level, the equilibrium is not the same, and languages classified as dominated at the global scale may in fact be contact languages, like, for instance, Nenge in Saint-Laurent of Maroni, or Brazilian Portuguese in St Georges of Oyapock, with positive associations (Léglise 2004). We can thus raise the issue of how legitimate a global overview can be if it corresponds neither to any one particular exemplary case, nor to the sum of local particularities, nor even to their smallest common denominator.

While most speakers of these different languages do in fact belong to "minority" communities, their languages are not minorized as a direct consequence of this. The notion of "minorized language" refers in this case to a definition which acknowledges various macroand microlinguistic features, as proposed by Kasbarian (1997). Like Kasbarian, we retain of 
the different macro approaches that a "minorized language is a language whose lack of autonomy, status, diffusion, functional distribution and standardization makes up objective characteristics derived from macrolinguistic description." We retain from microlinguistic approaches the idea that they are "languages whose value is not recognized on the interactional scene by speakers of a sociolinguistically dominant language (official language, written language, contact language, language of schooling, backed by regulating and prescriptive norms), and that speakers of the minorized language conform to the usage and interactive norms set by their interlocutors." iii

Indigenous languages in particular are often labelled "minority languages" and generally categorized as "endangered languages" according to UNESCO's definition of the term : "A language is endangered when it is on a path toward extinction" (2003:2). In other words, the language does not fulfil the following criteria of linguistic vitality:

(1) Intergenerational language transmission

(2) Absolute number of speakers (the smaller a community is, the more likely it is to be endangered)

(3) Proportion of speakers within the total population

(4) Use in existing language domains

(5) Response to new domains and media

(6) Materials for language education and literacy

A language must fulfil all of these criteria to be considered in a situation of "linguistic vitality".

Kali'na, one of the six Indigenous languages of French Guiana, belonging to the Cariban family, is spoken in five countries: Brazil, France (French Guiana), Surinam, Guyana and 
Venezuela. It appears to be a minority language with respect to all the languages in Guyanese territory (official, regional, contact), as the number of speakers is estimated around $2800^{\mathrm{iv}}$, in other words less than $2 \%$ of the total population of the department. It is worth questioning whether this language is minorized, both at the departmental scale as well as at the more local scale of Kali'na-speaking communities, and if so, whether it is always minorized, or whether minoritizations and deminoritizations are sometimes perceptible in certain situations. Minoritization - in French "minorisation"- here refers to the concept as it is defined by Py and Jeanneret (1989), that is, as a way to conceptualize linguistic inequalities in a dynamic way, as a process "governed by the very development of oral interaction, constructed and constructible with each speech act."v

From the point of view of Amerindianist linguists, Kali'na could be considered to be "endangered" due to its intensive contact with other languages in French Guiana, which could lead to quite substantial changes in the lexicon and the morphosyntactic structure of the language $^{\mathrm{vi}}$. Indeed, Kali'na has been in contact with different languages since the beginning of the period of colonization, resulting in different degrees of influence (Renault-Lescure, 2004), and, more recently, with French, which appears to have a strong influence on the linguistic practices of current generations.

The aim of this article is to document the case of Kali'na as a minority language in French Guiana by, on the one hand, using both micro- and macrosociolinguistic levels of analysis, and on the other, questioning the static descriptive categories ("dominated language", "minorized language", "endangered language") available in the literature as they apply to the contrasted situation of Kali'na over a large geographical area and in varied interactive contexts. The fact that contact situations for Indigenous languages are most often approached 
as matters of the language death or endangerment must be questioned. While the terms may be pertinent in some cases ${ }^{\mathrm{vii}}$, they may not be for Kali'na.

The findings presented here are based on data gathered during three periods of field work. These data involve, on the one hand, a microsociolinguistic study of the interactions between children and young Kali' na speakers in a school setting and in the village (Alby 2001), and on the other, the analysis of results, as they pertain to Kali'na, collected during a large-scale survey through guided interviews in a school setting about spoken languages and related attitudes (see Léglise 2007 for methodology). There is also an analysis of speeches collected from oral media or written about the language.

In the first part of this article we will look at the macrosociolinguistic indicators we have of the minorization - in French "minoration" - of Kali'na. At the departmental scale, we are interested in attitudes with regards to Kali'na language and culture, and to epilinguistic comments by speakers. We shall raise the question of whether the minorization of this language is internalized by its speakers and in particular by the children. In the second part of the article, we will present a more local view of relationships between languages. Looking at the Awala-Yalimapo township in Western Guiana, which has been recognized as autonomous since 1989 and is inhabited primarily by Kali'na speakers, we will explore whether the effects of minorization change at the local scale, and also at the broader scale of the Kali'na linguistic community. In the third part, we will attempt to determine to what extent, as far as interaction is concerned, the alternations and code switching observed between Kali'na, French and Creole offer clues about the process of minoritization or deminoritization currently underway. 


\section{Some indicators of the minorization of Kali'na in French Guiana}

At the macrolinguistic level, the situation of Kali'na in French Guiana is one of a double minorization (Alby, 2005). Two languages are majorized through their status and their function, namely French, as the language of schooling and public institutions in general but also more and more as a contact language, and creoles ${ }^{\text {viii }}$, in their role as contact languages. This statutory domination is compounded by a "socio-racial stratification dating back to the period before the creation of the department", which has been uncovered by works in sociology and anthropology (namely Jolivet 1982, Collomb 1997) which distinguish “primitive" peoples (Indigenous and Maroons ${ }^{\mathrm{ix}}$ ) and "civilized" peoples (White Peoples and Creoles)

Different elements indicate that there is indeed a minorization of Kali'na and internalization of this attitude by speakers.

\subsection{Kali'na speeches depicting a situation of linguistic domination}

Summing up the positions of Kali'na speakers with respect to the linguistic situation in French Guiana is a delicate matter. Nevertheless a number of arguments appear to converge in epilinguistic speeches. In July 2003, a special report called "Indigenous languages of Guiana are resisting" appeared in the Indigenous magazine Okamag. Two articles clearly point to the dominance of two languages, French and Guyanese Creole. We can "sound the alert for the preservation of Kali'na which is considered to be endangered" to the extent that "young people speak their mother tongue less and less" switching instead to French and

Creole, considered by the author to be dominant languages. Another article makes the same claims: "At the dawn of the third millennium, I am saddened to see my mother tongue, 
Kali'na Aulan, disappearing under pressure from French and Creole." Furthermore, according to the author of the second article, the situation faced by Kali'na is the same in other countries where the language is spoken : "It is disappearing under pressure from Taki Taki $^{x}$ in neighbouring Surinam, and from Spanish in Venezuela."

Similarly, during a colloquium organized in Cayenne in May 2003 entitled "The writing of languages of Guiana", some participants brought up the fears of the Kali'na in the face of a Creole language hegemony, with the former accusing the latter of subjecting the language to the same domination which Guyanese Creole faced from French.

\subsection{The overcautious or minorizing attitude of politicians and the media}

The strong presence of French and, to a lesser extent, Creole in the Guyanese media (the majority of programs are in these two languages) majorizes them, even if over the last few years programs about Amerindian languages and English-based Creoles have started to appear. The Kali'na nonetheless generally believe that the media have no serious interest in their language. During a workshop testing the writing system adopted for Kali'na in 1998, not a single media representative was present to cover the event, despite invitations having gone out to them. These events, which take place every two months or so, are of great importance to the community, and the absence of the media was not appreciated by the organizers. ${ }^{\mathrm{xi}}$

Furthermore, Indigenous languages are only poorly represented, if at all, in the political arena, and completely absent from speeches made by non-Indigenous local politicians. As an example of this, during the $7: 30$ PM news program by Tele Guyane on RFO on August $20^{\text {th }}$ 2003, in an interview on multilingualism in St Georges of Oyapock, the mayor of the small Eastern Guyanese town mentioned that St Georges has a tri-lingual population speaking 
French, Portuguese and Creole, and that efforts were being made to accommodate these three languages in school settings. The speech made no mention of another language spoken in St Georges, namely Palikur, which has a large number of speakers (Leconte, Caitucoli 2003). The omission of any reference to this Indigenous language from the speech reinforces the hierarchy of official language/contact language(s), with the minorization of Indigenous vernacular languages.

Indigenous demands concerning the naming of towns (which recall the Kali'na origins of some of the current names-such as Kalani for Cayenne, Ilakupo for Iracoubo, etc) or buildings (such as a request to give a Kali'na name to a new middle school) have led some speakers to comment on the limited response to such claims among politicians and the media: "In Guiana, people prefer large-scale public debates about changing the name of the Rochambeau airport, and attempt to stifle projects aiming to see Indigenous names given to buildings." (Okamag, 07.2003, 6)

\subsection{Non-native minorizing speeches}

According to a number of non-Kali'na social agents (postal workers, doctors, pharmacists, school principals) ${ }^{\mathrm{xii}}$, there are several reasons which make it unnecessary to hire bilingual personnel for the benefit of the Kali'na-speaking population : "Kali'nas all speak French", "they give us no trouble", "they're a peaceful population". Pierre and Françoise Grenand (1985) have pointed out, concerning the reception of the foundation speech of the indigenous movement in Guiana, that "very few people could imagine that a Galibi" ${ }^{x i i}$ could be the author of such vigorous and violent words... Indigenous unfortunately live in the shadow of the image that they are timid people, populations of "grown-up children"”. 
It seems to us that the widely circulated image of an "inoffensive population" leads to a minorization of their culture, as the group appears not to require any particular adaptations, unlike other populations present in Guiana.

Unlike Maroon children, who are often seen by the school administration as a "problem group" for disciplinary purposes, Kali'na children do not elicit discipline-related complaints from their teachers, and are seen as "very pleasant". Rather it is this very "absence of problems" which is an issue, and Kali'na children are criticized for not being outspoken enough in class. There are discussions about setting up means of intervening in problems relating to the language and culture of the Maroons, but none about the language and culture of the Kali'na. Nevertheless Kali'na children and Maroon children have the same failure rate at school, and the silence of the Kali'na in the classroom has been related to a cultural phenomenon known since the 1970's as the "silent Indian child" (Dumont 1972, Philips 1972).

The comments and attitudes of teachers, which often reveal a lack of training in the area of Guyanese cultural diversity (Léglise and Puren 2005), can lead to a minorization of languages even if this was not the intent of the speaker. For example, during a class-room observation at Saint-Laurent of Maroni, despite a teacher's desire to have the students' languages enter into the classroom, his questions were met with embarrassed silence. In a heterogeneous class, with a majority of Maroon children and five Indigenous children (2 Kali'na and 3 Arawak), the teacher asked how to say a particular word "in Indian". The Indigenous children had different linguistic backgrounds: the Kali'na individually told the observer that they spoke their language, but the Arawak said they no longer spoke the Amerindian language of their ancestors but rather an English-based Creole, Sranan Tongo, also spoken by the Maroon children in the class. The teacher's misunderstanding of the individual linguistic backgrounds of his students led him to some hasty conclusions: the Maroon children had answered his 
question satisfactorily, but not the Indigenous, and he turned to the observer and said: "You see, they don't even know how to say it in their language". This certainly does not help develop a valorization of the group of Indigenous children, who happen to be numerically inferior, nor an appreciation of their individual languages.

1.4. Declared practices of Kali'na-speaking children : an integration of several layers of minorization?

A study carried out in a school setting, through individual semi-directive interviews with students around ten years old, showed that less than $4 \%$ of the studied population in the towns of Saint-Laurent of Maroni and Mana claims Kali'na as their first or second language (Léglise 2004). On a numerical scale, then, Kali'na children are clearly a minority in both towns. One of the questions in the interview was a self-evaluation of their first language skills (defined as the language spoken before the beginning of schooling): “do you speak your first language a little, well, or very well?”, “do you understand your first language a little, well, or very well?". The following table shows the percentages of positive responses: self-evaluation of the mother tongue was considered to be positive overall if the students' answers were "well or very well". In Saint-Laurent, only half the children with Kali'na as L1 claimed to speak the language well, unlike children claiming Haitian Creole or Aluku, other minority languages in this town (Léglise and Migge 2005). 


\begin{tabular}{|l|l|l|}
\hline L1 & $\begin{array}{l}\text { Positive self-evaluation } \\
\text { for production }\end{array}$ & $\begin{array}{l}\text { Positive self-evaluation } \\
\text { for comprehension }\end{array}$ \\
\hline Kali'na & $50 \%$ & $80 \%$ \\
\hline Aluku & $78 \%$ & $100 \%$ \\
\hline Haitian Creole & $100 \%$ & $100 \%$ \\
\hline
\end{tabular}

Tab 1. Self-evaluation in three minority L1s in St Laurent

The rates are even lower for Kali'na-speaking children being educated in the town of Mana, where two thirds of the children claim they only speak and understand their mother tongue "a little". This seems to betray an attitude which minorizes the use of a language which is claimed as the L1 but which is diminished because the speaker claims: "I speak it, but not well, not really, etc" as if to be forgiven for speaking it and to not completely accept it. One wonders to what extent these self-evaluations reflect an internalization for the children of the minorization of their language and culture on a more global level. One also wonders whether these attitudes reflect, at least partially, the negative evaluation by adults and elders of the competence levels of young speakers, a point to which we will return.

Taking into account the four preceding points, Kali'na appears to be a globally minorized language. This statement must however be further qualified with reference to two recent changes in different directions. On the one hand, we notice a tendency to deminoritize Kali'na through the media, thanks to the emergence of Kali'na media (a Kali'na-French bilingual newspaper and radio station, as well as a multilingual ${ }^{\mathrm{xiv}}$ radio station, Radio Galibi, broadcast from Surinam but available on the West Coast of Guiana) and also room for Kali' na ${ }^{\mathrm{xv}}$ on the local radio programs, whereas until recently, only Creole and French were used. ${ }^{\text {xvi }}$

On the other hand, we notice in the Kali'na language, but most specifically in the lexicon, the reinforced presence of French. The language is in the midst of a phase of massive borrowing from French, coupled with the loss of certain semantic categories already affected in previous 
generations (such as numerals, colors, or kinship terms). There are several explanations for this phenomenon: compulsory schooling since 1969 and the image of French as a prestige language (Renault-Lescure 1985) which allows speakers "a footing in the world of the Whites and Creoles who hold local power."

\section{The minorization of Kali'na with respect to the particular situation in the village of} Awala-Yalimapo

The 900 inhabitants township of Awala-Yalimapo has a number of particularities which distinguish it from other Guyanese townships as well as from other Kali'na villages. These particularities have the potential to result in a majorization of the language of its inhabitants. This township, almost a mono-community and rather isolated geographically, is the birth place of the Indigenous protest movement in French Guiana ${ }^{\text {xvii }}$, and some of the inhabitants are known at the local and national levels. Having become a symbolic place, AwalaYalimapo has become a compulsory stop during any ministerial visit to Guiana (Collomb 1997).

Kali'na is spoken almost everywhere there, not only at home and for shopping but at the town hall and post office, two main symbols of French Administration and French presence in Guiana. Some political speeches are in Kali'na and during the last municipal elections, the pamphlet for one of the two electoral lists was bilingual in French and Kali'na. An examination of exchanges between children at school (Alby 2001) reveals that Kali'na plays an important role in the playground and partly in the classroom, with bilingual speeches present at all times. The language is also present at school under the auspices of a project called "bilingual and cultural mediators" during which three hours are devoted to Kali'na language study every week. In Awala, Kali'na appears to be making inroads into domains 
usually reserved for French—or Guyanese Creole—in the rest of the department, to the point that we might posit the idea of a local minorization of French.

The specific situation in this township therefore has consequences on language use but also on instituted norms and related attitudes. We see, for example, that the inhabitants consider standard the way they speak, compared with other varieties of Kali'na spoken in French Guiana. Thus a survey carried out in 1986 by Odile Lescure among the inhabitants of AwalaYalimapo showed that a majority of adults there considered Awala and the neighbouring region to be the area where Kali'na is spoken best. Furthermore, the other varieties of Kali'na are being minoritized and their speakers are submitting to this minoritization, as seen in the following extract from an interview with a Kali'na woman (R) from the village of YanouBellevue: "this is no good, I have made a mistake in Kali'na... you see, the Indians of Awala say that the people of Iracoubo don't speak Indian well. They say that we mix it with Creole, whereas they speak Indian well." This comment led the researcher (E) to ask her to elaborate:

E but when you speak with the (.) with the people from Awala (.) they say things about the way you speak?

$\mathrm{R} \quad$ they criticize it (quietly and with a smile)

E really? why do they criticize it?

R I don't know (2) because we don't speak (.) real KALI'NA' (...) because we mix it (...) that's why

E what do you mix it with'

$\mathrm{R} \quad$ with Creole

E hmmm

R we mix Kali'na with Creole (...) but they criticize ours because THEY speak it well' 
E yes (.) but what does it mean to speak Kali'na well?

$\mathrm{R}$ well, I don't know (...) he knows (...) but we have to speak Kali'na (...) I mean (...) Kali'nas have an accent (.) but we' (.) we just speak Kali'na like that

The declared practices of Kali'na children from Awala show contrasting results on this point. Results from an investigation in a school setting appear to confirm the fact that locally, minorizations seem to be reversible. In Awala, the numbers for self-evaluation for Kali'na production and comprehension are much higher than in other cities in the region, as two thirds of children claim to speak their language well or very well. As seen in table 2, the numbers jump from $36 \%$ or $50 \%$ positive self-evaluation to $76 \%$ for production $^{\text {xviii }}$, which indicates a local majorization of Kali'na. Nonetheless, a rate of $76 \%$ positive self-evaluation is still considerably less than the very good results gotten for majority languages in other towns, which are closer to $100 \%$ (as is the case for speakers of French, Guyanese Creole, and Ndyuka, a majority English-based creole spoken in the West). There are therefore $24 \%$ of children in Awala who claim Kali'na as L1 who feel they can only speak it "a little", which supports the trend observed in the two cities in the region and which could again be explained as an effect of the comments of elders and adults.

\begin{tabular}{|l|l|l|l|l|}
\hline & \multicolumn{2}{|l|}{$\begin{array}{l}\text { Positive self-evaluation } \\
\text { for production }\end{array}$} & \multicolumn{2}{l|}{$\begin{array}{l}\text { Positive self-evaluation for } \\
\text { comprehension }\end{array}$} \\
\hline & Kali'na L1 & French L2 & Kali'na L1 & French L2 \\
\hline Mana & $34 \%$ & $66 \%$ & $34 \%$ & $66 \%$ \\
\hline St Laurent & $50 \%$ & $66 \%$ & $80 \%$ & $64 \%$ \\
\hline Awala & $76 \%$ & $35 \%$ & $90 \%$ & $60 \%$ \\
\hline
\end{tabular}

Tab 2. Positive self-evaluation in Kali'na L1 and French L2 
Furthermore, the positive evaluation rate in $\mathrm{L}^{\mathrm{xix}}$ correlates to a very low rate of positive evaluation in French L2 since only 35\% of participating children in Awala (Kali'na L1) claimed to speak French well or very well. We must therefore ask ourselves whether this relatively good evaluation of their competence levels in Kali'na, as well as the particular situation in this village, makes these children relatively linguistically insecure in French. This general tendency in Kali'na children - that which correlates a positive self-evaluation in one language with a negative evaluation in another ${ }^{\mathrm{xx}}$ - differs sharply from the observations made at this stage in the survey for responses of child speakers of other languages of Guiana.

Whatever the situation may be, Awala-Yalimapo is particular in the high value associated with Kali'na, with children claiming to speak Kali'na more than their peers, whether these be their friends or siblings. Indeed, $82 \%$ of children claim to speak Kali'na to their friends, and say that only $70 \%$ of their friends respond in the same language. These percentages are respectively $75 \%$ and $62 \%$ for siblings. There seems to be a positive connotation to declaring oneself a better speaker of Kali'na than one's friends and siblings.

All these elements lend support to the idea, on the one hand, of the local majorization of Kali'na and the local variety spoken there, and on the other hand, the resulting minorization of other spoken languages, such as French and other non-local varieties of Kali'na.

\section{Interactions of youths as indicators of the minoritization or vitality of the language ?}

In the bilingual speech of Kali'na children, we notice competition between French lexical items and Kali'na lexical items or older borrowings, the children preferring the French form even if they are familiar with the other. This process is manifested in bilingual speech in the form of insertions or inserted mixing, using terminology from Auer (1999). This mixing is 
felt by a number of Kali'na to be an indicator of a process of minoritization. This is seen in the following extract from Okamag (2003): "Let us mention another serious problem: that of speaking one's language properly, with no borrowing, or as little as possible, of foreign words, which disfigure or denaturalize our language. [...]. When we hear some people speak Kali'na these days, there are sometimes more French or Creole words in their sentences than Kali'na. [...]. Some would be better off simply speaking French or Creole, rather than butchering their linguistic heritage!"

In children as well, mixing is felt to be very negative, as seen in the following comments by V., a ten year old Kali'na girl:

E do you know anyone who speaks Kali'na poorly?

V yes, M-Y

E what does it mean to speak poorly?

V she doesn't understand (.) she makes mistakes (.) when she doesn't know the Kali'na word she says it in French

E do you think you speak French well?

V no

E what do you not say right in French ?

V words

E do you sometimes mix French and Kali'na?

V yes (.) it's a bad thing to mix

E who do you mix languages with?

V M-Y. (.) with J. (.) with the girls in my class 
In interactions we see negative reactions when mixed forms are used, leading to a minoritization of bilingual speech:

M-Y owi carbet

V anekalikili-anukutipa wa français ta?
[ $a$ carbet]

[can't you say it in French?]

This minoritization of bilingual speech is also seen in the declared practices of children from Awala: while only $18 \%$ of children claim their friends mix languages or alternate while speaking-low results which do not correspond to real practices we have just describednone of them admits to mixing himself. Students say they use either Kali'na (82\%) or French (12\%). The behaviour of girls and boys is different on this point, as seen in table 3:

\begin{tabular}{|l|l|l|l|l|}
\hline $\begin{array}{l}\text { Communication } \\
\text { entirely in Kali'na }\end{array}$ & Friends / child & child / friends & Siblings / child & Child / siblings \\
\hline Awala girls & $55 \%$ & $77 \%$ & $66 \%$ & $77 \%$ \\
\hline Awala boys & $\mathbf{9 0 \%}$ & $\mathbf{1 0 0 \%}$ & $72 \%$ & $72 \%$ \\
\hline
\end{tabular}

Tab 3. Exclusive use of Kali'na, among siblings or friends.

Kali'na thus appears for boys to be an in-group code, with a powerful identity-building function, as almost all exchanges with friends are said to be in Kali'na. Among girls, we see traces of the idea already found in the comments of elders and adults that it is better to speak both languages well rather than half-way: girls claim they never communicate partly in French but rather entirely in one language or the other. They point to a difference with their friends, who do mix (33\% of communication from their friends is partly in French and partly in Kali'na, but they respond either in Kali'na, in $77 \%$ of cases, or in French, in $22 \%$ of cases, but never mixing the two), as seen in table 4 . These claims are comparable to those made about communication among siblings, where Kali'na use seems to be stronger. 


\begin{tabular}{|l|l|l|l|l|}
\hline $\begin{array}{l}\text { Communication } \\
\text { French in } \\
\text { entirely) }\end{array}$ & Friends to child & Child to friends & Siblings to child & Child to siblings \\
\hline Awala girls & $\mathbf{3 3 \%} / 0 \%$ & $\mathbf{0 \% / 2 2 \%}$ & $10 \% / 10 \%$ & $\mathbf{0 \%} / \mathbf{1 0 \%}$ \\
\hline Awala boys & $0 \% / 0 \%$ & $0 \% / 0 \%$ & $9 \% / 0 \%$ & $\mathbf{1 8 \% / 0 \%}$ \\
\hline
\end{tabular}

Tab 4. Use of French among siblings or friends

These results conform to the actual practices of children, where we notice differences between the speech of girls and that of boys in the classroom and in the playground. Alby (2001) has shown the net tendency for girls to use French in one situation and Kali'na in another, whereas for boys, code switching with a Kali'na matrix remains the same.

In contact situations, we often see a minoritization of mixing and code-switching in speech. The observed mixed variety, however, is equally rich in meaning and different values. We can propose that the mixed variety in adolescent boys and young male adults is an in-group code, a variety with an identity-building value. Furthermore, it appears to us as a sign, in children learning their language, of exploratory and playful behaviour towards language (Pochard 1993). The laughter of two boys upon hearing the language mix produced by B attests to this:
B kama'
[ go on !]
JP do' (.) sikap(i)i' (5) kama'
[go on $]$
B it 's a (.) PELO
[it's a $d o g]$

$\underline{\text { (laughter) }}$

Despite the fears of speakers in the face of language loss or death, which young speakers' speech represents to them, it is useful to observe in greater detail whether there is really a 
process of loss at the level of the language. Certainly at a lexical level we see many changes in several categories: nouns, adverbs, and, to a lesser extent, verbs. Thomason (2001) identifies different degrees of the process of borrowing and, in her opinion, a change is not major as long as the morphosyntactic structure is not affected. Renault-Lescure (2003) notes some changes at the morphosyntactic level in Kali'na, which we must examine to determine whether they represent an intrasystemic or intersystemic change.

\section{Conclusion}

In a situation of a "conflicting" multilingualism with official language, contact languages, and minority vernacular languages with very few speakers (as is the case for quite a few Indigenous languages in the world), language contact often eventually leads to the death of the minority languages involved. Of the twenty or so Indigenous languages spoken at the beginning of the period of colonization, only six remain in French Guiana, and in endangered conditions.

At the linguistic and microsociolinguistic levels, our conclusion regarding Kali'na is divided : language contact has led to numerous lexical changes and the question of whether language contact has brought about morphosyntactic change is still unresolved. Nonetheless, language games, alternations, bilingual speech as a code among adolescents (Alby 2003), with identitybuilding and cryptic functions, are signs of vitality in that the language is alive and functional as a linguistic resource (Mondada 2002) for young speakers who, as the first generation attending secular schools, are experiencing the difficulties of drops in status and the creation of social outcasts (Collomb 2001).

At a global level, small victories have been won for outside recognition of Kali'na language and culture. At the community level, language use is maintained, and there is also the 
development of identity, linguistic and cultural claims, signs of increased awareness on the part of the speakers.

The specific situation in the Awala-Yalimapo community is paradoxical, with its majorization of Kali'na and the local minoritization of French and of mixed speech in some contexts. On the one hand, the community is a symbol of a linguistic and cultural conquest, an element of pride for the community, but on the other hand, this very same symbol participates in the minoritization that affects Kali'na speakers: the Awala variety sometimes appears as a standard variety, minorizing the varieties spoken outside the village as well as those of young speakers in the community.

The data we have presented call for the use of concepts which relate to processes, such as "minoritization" or "deminoritization", rather than static concepts such as "minorized language" or "minorization". These concepts are also useful in discussing the criteria for "endangered languages" proposed by UNESCO, such as intergenerational language transmission or use in existing language domains as well as in new domains and the media. It is very difficult to generalize along such lines, and to find clear answers concerning indicators of vitality or endangerment. The analyses of microsituations demonstrate quite clearly that linguistic practices vary tremendously from one family to another, from one village to another, or from one location within a village to another.

\section{Notes}

\footnotetext{
${ }^{\mathrm{i}}$ See also the special issue of the International Journal of the Sociology of Language (2002) edited by J. A. Fishman: "Focus on Diglossia".

${ }^{\text {ii }}$ Particularly in some places, such as villages, markets, rivers.

iii «une langue minorée est une langue dont l'absence d'autonomie, de statut, de diffusion, de distribution fonctionnelle et de standardisation constituent des caractéristiques objectives issues de la description macrolinguistique. ». C' «est une langue dont les valeurs ne sont pas reconnues sur la scène interactionnelle par les locuteurs d'une langue sociolinguistiquement dominante (langue officielle, écrite, véhiculaire, scolaire, dotée de normes régulatrices et prescriptives), les locuteurs de la langue minorée se conformant pratiquement aux normes d'usage et d'interaction produites par leurs interlocuteurs. »

${ }^{\text {iv }}$ From Collectif (2003).
} 
${ }^{\mathrm{v}}$ Un processus « régi par le développement même de l'interaction verbale, construit et à construire dans chaque instance de discours ».

${ }^{\mathrm{vi}}$ Opinions vary on this point, some scholars considering that morphosyntactic criteria should be given more weight than lexical.

${ }^{\text {vii }}$ When the population becomes extinct, or when there are no remaining speakers for example.

viii Traditionnaly a French-lexified creole, Guyanese Creole, and yet on the Western part of Guiana also Englishbased creoles such as Ndyuka or Sranan Tongo.

${ }^{\text {ix }}$ The populations of African-descent who originate from Suriname (see Price, 2002), also called Businenge.

${ }^{x}$ A term probably referring to Sranan Tongo but see Léglise and Migge (2004).

xi "RFO could not attend the second workshop, Saturday April 12th, which took place in Bellevue-Yanou and gave as an excuse that Bellevue was too far. If RFO had had to cover the preparation of aouara soup in Iracoubo, they would have been there, but a Kali'na workshop is somehow not worth their time. Thanks." (Okamag, 07.2003: 6)

${ }^{x i i}$ During non-directive interviews (see Léglise 2004b).

xiii Non-native name for the Kali'na until they reclaimed the use of their autonym.

${ }^{\text {xiv }}$ Kali'na-Dutch-Sranan Tongo.

${ }^{x v}$ A popular Kali'na language program, on the radio at Awala, which gives local news. There is also a program on Palikur, another Indigenous language, as well as a radio presenter who is ethnically Palikur.

${ }^{x v i}$ This appearance of Indigenous languages in the media primarily concerns coastal languages, which raises the issue of the potential minoritization of languages of the interior.

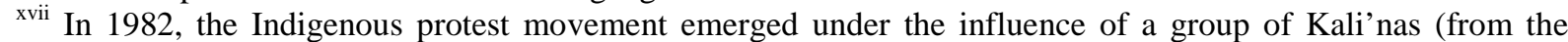
generation educated in Catholic boarding schools), leading to, in 1983, the first explicit linguistic claim against the state which was deforming family names and refusing Indigenous first names. In 1984, during the first assembly of Indigenous in Guyana, a bilingual speech (written and oral) was produced, using “i which differs from the French transcription system for the language. In 1998, after a number of workshops and collaboration with linguists, the Kali'na came to an agreement about their writing system, during the YanouBellevue meeting. They created a workgroup about Kali'na language and culture at that time which is still active today.

${ }^{x v i i i}$ We can also see a gap between production and comprehension, a phenomenon which is found in situations of immigration where, after a period of schooling and use of French by successive generations, there is a passive usage of L1 (comprehension) and less and less production. Kali'na children currently in CM2 (5th grade) correspond to the second schooled generation.

${ }^{\text {xix }}$ Girls and boys must be distinguished in Awala because unlike Kali'na L1 boys, who all claim they speak Kali'na very well, only $42 \%$ of girls claim they speak it very well. More than half the girls interviewed thought of themselves as only speaking Kali'na "a little". These numbers are much higher for comprehension. Boys claim to know French only poorly, whereas for girls, these numbers are higher by 20 to $35 \%$ !

${ }^{\mathrm{xx}}$ Similarly, if we look at children claiming Kali'na as L2, we are surprised to find that none of the investigated children claim to speak the language well or very well. These poor evaluations are often accompanied by very good self-evaluations for French, which is claimed as L1 (100\% of interviewed children claimed to speak it well or very well).

\section{Bibliography}

Alby, S. (2001). Contacts de langues en Guyane française: une description du parler bilingue kali'na-français, Unpublished Ph.D. thesis, Université de Lyon II, Lyon.

Alby, S. (2003). Discours bilingue chez les jeunes kali'na d'Awala-Yalimapo: l'émergence d'un parler jeune ?». Paper presented at the Third Sociolinguistic Conference : Pratiques et représentations des contacts de langues dans des contextes de mobilité, Lyon. 
Alby, S. (2005) Une approche bilinguiste du contact de langues : discours bilingues d'enfants kali'na en situation scolaire. Trace 47. Mexico : CEMCA, 96-112.

Aracil, L. V. (1965). Conflit linguistique et normalisation dans l'Europe nouvelle, Nancy, CUE.

Auer, P. (1999). From codeswitching via language mixing to fused lects: toward a dynamic typology of bilingual speech. International Journal of Bilingualism vol.3(4), 309-322.

Collomb, G. (1997). La question amérindienne en Guyane. Formation d'un espace politique. In Anthropologie du politique, M. Abélès. and H-P. Jeudy (eds.), 41-58. Paris : Armand Colin.

Collomb, G. (2001). De l'indien à l'indigène. L'internationalisation des luttes amérindiennes en Guyane et les enjeux de l'autochtonie. Recherches Amérindiennes au Québec, vol. XXXI (3), 37-47.

Collectif, (2003). Les langues de Guyane. In Les langues de France, B. Cerquiglini (dir.), 269-303. Paris : PUF.

Dumont, R. (1972). Learning English and how to be silent: studies in Sioux and Cherokee classrooms. In Functions of language in the classroom, C. Cazden, V. John and D. Hymes (eds.). New York: Colombia University.

Ferguson, C. (1959). Diglossia. Word 15, 325-340.

Ferguson, C. (1991). Diglossia revisited. Studies in Diglossia. University of Texas Press, 214234.

Fishman, J. A. (1971). Sociolinguistique. Paris \& Labor Bruxelles: Nathan.

Fishman, J.A. (ed.) (2002). Focus on Diglossia. International Journal of the Sociology of Language 157, Berlin \& New-York: Mouton de Gruyter.

Grenand, P., Grenand, F. and Menget, P. (1985). La Question amérindienne en Guyane française, éléments de synthèse. Ethnies vol. 1 (1-2), Survival International France, 54-57. 
Haugen, E. (1989). Minority language today. Edimbourg: Edinburg University Press.

Jolivet, M.-J. (1982). La question créole. Essai de sociologie sur la Guyane française. Paris : Orstom.

Jolivet, M.-J. (1991). Langues dominées et langues dominantes en Guyane: pratiques comerciales et pratiques scolaires à Mana. Cahier des sciences humaines 27, 497-515.

Kasbarian, J.-M. (1997). Langue minorée et langue minoritaire. In Sociolinguistique, concepts de base, M-L. Moreau (ed). Bruxelles : Mardaga, 185-188.

Leconte, F. and Caïtucoli, C. (2003). Contacts de langues en Guyane: une enquête à St Georges de l'Oyapock. In Contacts de langues: Modèles, typologies, interventions, J. Billiez (ed), 37-59. Paris: L'Harmattan.

Léglise, I. (2004). Langues frontalières et langues d'immigration en Guyane Française. Glottopol 4, 108-124.

Léglise, I. (2005). Contacts de créoles à Mana: répertoires, pratiques, attitudes et gestion du plurilinguisme. Etudes Créoles XXVIII (1), 23-57.

Léglise, I. (2007) Des langues, des domaines, des régions. Pratiques, variations, attitudes linguistiques en Guyane. In Pratiques et représentations linguistiques en Guyane : regards croisés, I. Léglise and B. Migge (eds) Paris : IRD Editions, 29-47.

Léglise, I. and Migge, B. (2005). Contacts de langues issus de mobilités dans un espace plurilingue: approches croisées à St Laurent du Maroni. In Pratiques et représentations des contacts de langues dans des contextes de mobilité, C. Van den Avenne (coord.). Paris : L'Harmattan, 75-94.

Léglise, I. and Migge, B. (2006). Towards a comprehensive description of language varieties: A consideration of naming practices, ideologies and linguistic practices, Language in Society 35, 313-339. 
Léglise, I. and Puren, L. (2005). Usages et représentations linguistiques en milieu scolaire guyanais. Univers créoles 5. St Denis de la Réunion : Anthropos, 67-90.

Mondada, L. (2002). Pour une approche émique de la catégorisation des ressources linguistiques par les locuteurs. Cahiers de l'Institut de Linguistique de Louvain 28(3-4), 2335.

Philips, S. (1972). Participant structures and communicative competence: Warm Springs children in community classrooms. In Functions of language in the classroom, C. Cazden, V. John and D. Hymes (eds.). New York : Colombia University.

Pochard, J-C. (1993). Profil(s) d'apprenant(s). Paper presented at the $9^{\text {th }}$ international conference Acquisition d'une langue étrangère: perspectives et recherches, ms.

Py, B. and Jeanneret, R. (dir.) (1989). Minorisation linguistique et interaction. Genève: Droz. Price, R. (2002). Maroons in Suriname and Guyane: How many and where. New West Indian Guide 76, 81-88.

Renault-Lescure, O. (1985). Evolution lexicale du galibi, langue caribe de Guyane française, Unpublished Ph.D. thesis, Université Paris IV, Paris.

Renault-Lescure, O. (2005). Intégration grammaticale des emprunts en kali'na (langue caribe de guyane française) : stratégies différenciées. In Chamoreau C. and Lastra Y. (eds) Dinamica linguistica de las lenguas en contacto. Mexico: Universidad de Sonora.

Thomason, S. (2001). Language contact: an introduction. Edinburgh: Edinburgh University Press.

Tiouka, F. (1985). Nana inonoli, nana kinipinanon ilompo nana iseman (Notre terre nous l'aimons, et nous y tenons / Adresse au gouvernement et au peuple français). Ethnies vol. 1(12) $n^{\circ} 1-2,7-10$. 
UNESCO (2003). Language vitality and endangerement. Report approved 31 March 2003 by the participants of the International Expert Meeting on the UNESCO program "Safeguarding of Endangered Languages". Paris-Fontenoy.

Appendix 1

Map 1. Regional languages in French Guiana 


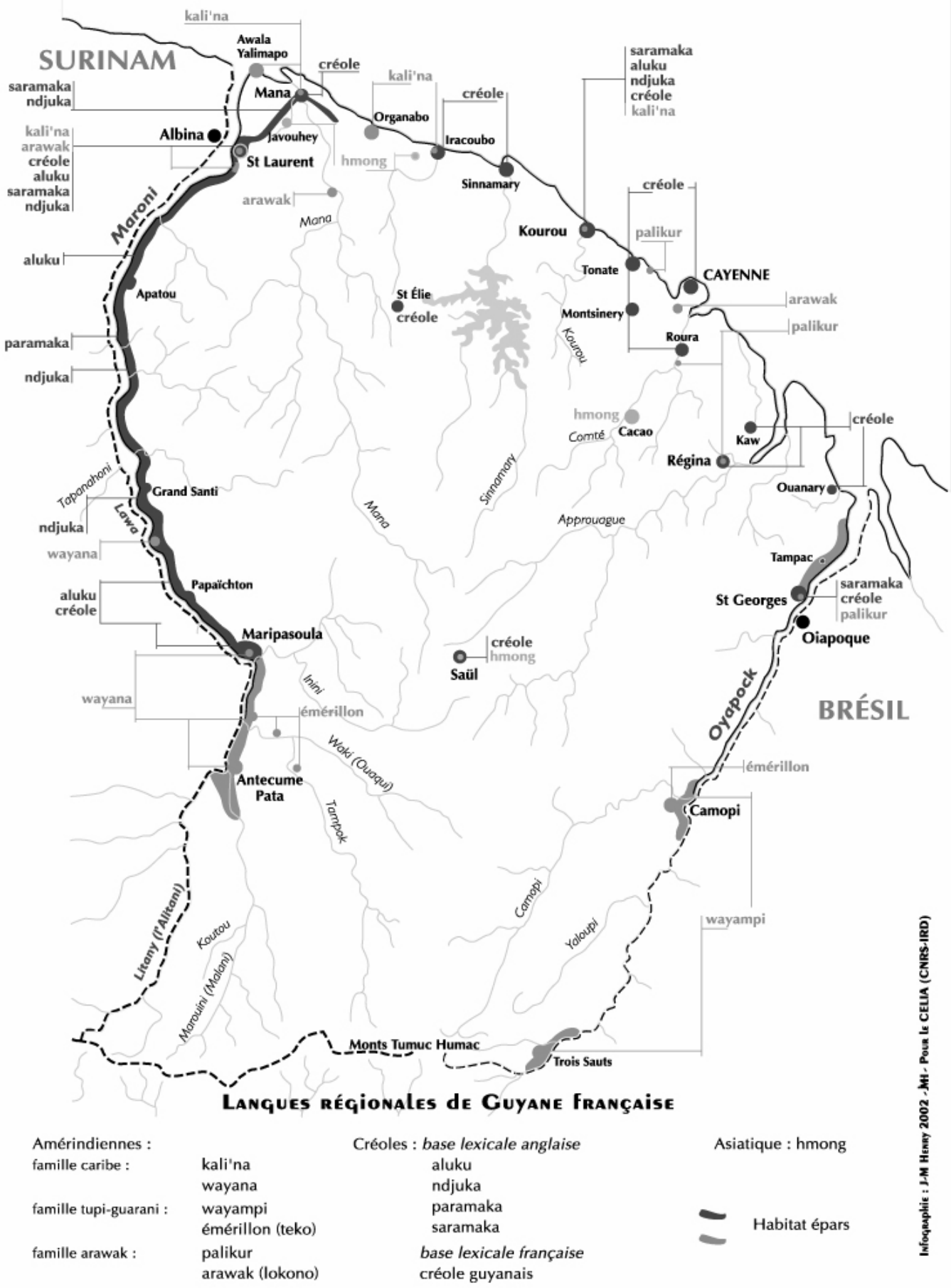

